\title{
The influence of distal screw length on the primary stability of volar plate osteosynthesis-a biomechanical study
}

\author{
Sebastian F. Baumbach ${ }^{1 *}$ D, Alexander Synek ${ }^{2}$, Hannes Traxler ${ }^{3}$, Wolf Mutschler ${ }^{1}$, Dieter Pahr ${ }^{2}$ and Yan Chevalier ${ }^{4}$
}

\begin{abstract}
Background: Extensor tendon irritation is one of the most common complications following volar locking plate osteosynthesis (VLPO) for distal radius fractures. It is most likely caused by distal screws protruding the dorsal cortex. Shorter distal screws could avoid this, yet the influence of distal screw length on the primary stability in VLPO is unknown. The aim of this study was to compare 75 to $100 \%$ distal screw lengths in VLPO.
\end{abstract}

Methods: A biomechanical study was conducted on 11 paired fresh-frozen radii. HRpQCT scans were performed to assess bone mineral density (BMD) and bone mineral content (BMC). The specimens were randomized pairwise into two groups: $100 \%$ (group A) and $75 \%$ (group B) unicortical distal screw lengths. A validated fracture model for extra-articular distal radius fractures (AO-23 A3) was used. Polyaxial volar locking plates were mounted, and distal screws was inserted using a drill guide block. For group $A$, the distal screw tips were intended to be flush or just short of the dorsal cortex. In group B, a target screw length of $75 \%$ was calculated. The specimens were tested to failure using a displacement-controlled axial compression test. Primary biomechanical stability was assessed by stiffness, elastic limit, and maximum force as well as with residual tilt, which quantified plastic deformation.

Results: Nine specimens were tested successfully. BMD and BMC did not differ between the two groups. The mean distal screw length of group A was $21.7 \pm 2.6 \mathrm{~mm}$ (range: 16 to $26 \mathrm{~mm}$ ), for group B $16.9 \pm 1.9 \mathrm{~mm}$ (range: 12 to $20 \mathrm{~mm}$ ). Distal screws in group B were on average $5.6 \pm 0.9 \mathrm{~mm}$ (range: 3 to $7 \mathrm{~mm}$ ) shorter than measured. No significant differences were found for stiffness $(706 \pm 103 \mathrm{~N} / \mathrm{mm}$ vs. $660 \pm 124 \mathrm{~N} / \mathrm{mm})$, elastic limit (177 $\pm 25 \mathrm{~N}$ vs. $167 \pm 36 \mathrm{~N})$, maximum force $(493 \pm 139 \mathrm{~N}$ vs. $471 \pm 149 \mathrm{~N})$, or residual tilt $\left(7.3^{\circ} \pm 0.7^{\circ}\right.$ vs. $\left.7.1^{\circ} \pm 1.3^{\circ}\right)$.

Conclusion: The $75 \%$ distal screw length in VLPO provides similar primary stability to $100 \%$ unicortical screw length. This study, for the first time, provides the biomechanical basis to choose distal screws significantly shorter then measured.

Keywords: Colles' fracture, Distal radius fracture, Biomechanics, Volar plate osteosynthesis, Polyaxial volar locking plates, Screw length, Fracture

\section{Background}

Recent studies have reported complication rates following volar locking plate osteosynthesis (VLPO) for distal radius fractures of up to $18 \%[1,2]$. Two of the most common complications are extensor tendon irritation and attritional tendon ruptures $[1,3,2]$. These are attributable either to

\footnotetext{
* Correspondence: sebastian.baumbach@med.uni-muenchen.de 'Department of Trauma Surgery, University Hospital of Munich (LMU), Campus Innenstadt, Nußbaumstrasse 20,80336 Munich, Germany Full list of author information is available at the end of the article
}

direct damage during the operation (drilling, depth gauge) or secondary due to dorsodistal screw protrusion [4-6].

Dorsal screw protrusion might be an avoidable complication, especially for extra-articular fractures (AO-23 A3), which are the most common ones $[7,8]$. The AO Foundation [9] as well as Campbell's Operative Orthopaedics [10] recommends using distal screw length 2 to $4 \mathrm{~mm}$ shorter than measured. However, the effect of shorter distal screws on the primary stability of the VLPOs remains unclear. Preliminary data on synthetic bones indicates that $75 \%$

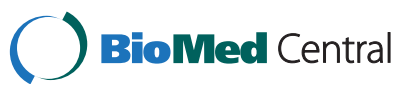

(C) 2015 Baumbach et al. Open Access This article is distributed under the terms of the Creative Commons Attribution 4.0 International License (http://creativecommons.org/licenses/by/4.0/), which permits unrestricted use, distribution, and reproduction in any medium, provided you give appropriate credit to the original author(s) and the source, provide a link to the Creative Commons license, and indicate if changes were made. The Creative Commons Public Domain Dedication waiver (http://creativecommons.org/publicdomain/zero/1.0/) applies to the data made available in this article, unless otherwise stated. 
distal screw length provides comparable primary stability to $100 \%$ unicortical screw length [11].

Shorter distal screws are the most promising approach to avoid dorsal screw protrusion. Therefore, it is indispensable to investigate the effect of distal screw length on the primary stability of VLPO. Consequently, the aim of this study was to compare 75 to $100 \%$ distal screw lengths in VLPO using human fresh-frozen radii and an established biomechanical fracture model for extra-articular distal radius fractures (AO-23 A3). The study's null hypothesis was that unicortical $100 \%$ distal screw lengths provide superior primary stability compared to $75 \%$ distal screw lengths in VLPO.

\section{Methods}

This biomechanical study was conducted on fresh-frozen human radii using a validated fracture model for extraarticular distal radius fractures (AO-23 A3). The local ethics committee approved the study (LMU \#409-13). The outcome parameters of interest were stiffness, elastic limit, maximum force, and residual tilt of the distal fragment.

Eleven paired fresh-frozen radii were obtained from the Centre of Anatomy and Cell Biology, Medical University of Vienna, Austria. Radii were randomized pair-wise, side alternating into a $100 \%$ unicortical distal screw length group (group A) and a $75 \%$ distal screw length group (group B). They were then cut to $14-\mathrm{cm}$ length. High-resolution peripheral quantitative computer tomography scans (HRpQCT, XtremeCT, Scanco Medical
AG, Switzerland) were performed. Radii presenting previous fractures, severe osteoarthritis, or bone lesions were excluded. Bone mineral density (BMD) and bone mineral content (BMC) were computed [12] to assess possible group differences.

\section{Specimen preparation}

The general preparation has been outlined in detail previously [13]. In brief, the radii were cleaned of all soft tissue and multidirectional, angular stable volar plates (APTUS 2.5 ADAPTIVE TriLock Distal Radius Plate, A-4750.61, Medartis Inc., Basel, Switzerland) were mounted just proximal to the watershed line. The plates were fixed to the radius shaft using four bicortical locking screws (Fig. 1C, screws 9, 10, 12, and 13).

A drill guide block (Medartis A-2723 01/02) was mounted onto the distal plate, which assured uniform distal screw orientation. Following drilling, distal screw length was measured. Distal locking screw lengths were chosen according to the previously defined groups. For group A (100\%), the screw tips were intended to be flush or just short of the dorsal cortex (Fig. 1A). In group B (75 \%), a target screw length of $75 \%$ was calculated and rounded to the next available screw length (Fig. $1 \mathrm{~B}, \mathrm{C}$, screws $1-5$ and 8 ). Screws were available in 2-mm increments.

Following distal screw insertion, a 10-mm dorsal wedge osteotomy simulating a dorsally unstable fracture was performed using an oscillating handsaw. The osteotomy

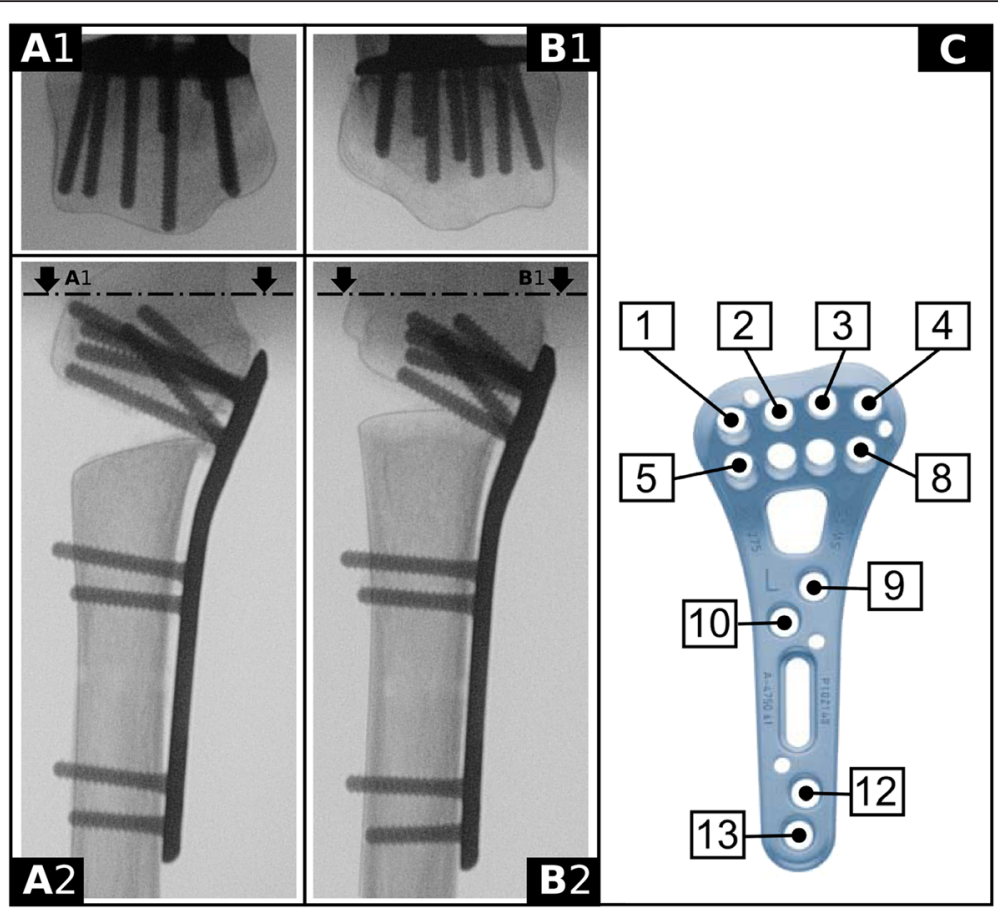

Fig. 1 Outline of the $100 \%$ (group A) and $75 \%$ distal screw length (group B) setups. A unicortical, $100 \%$ distal screw length (Group A). B $75 \%$ distal screw length (Group B). 1 Skyline view, 2 lateral radiograph 
location resembled the in vivo fracture location and was chosen based on previous studies [14, 13]. Care was taken to completely separate the volar cortex (1-mm gap).

Each specimen was then embedded using two custommade aluminium jigs. The load axis was defined proximally by the medullary canal and distally slightly dorsoradial to the centre of the crista subdividing the fossa lunata and scaphoidea. The proximal $40 \mathrm{~mm}$ of the shaft and a shallow edge of the distal articular surface of the radii were embedded in polyurethane (PUR, FDW HG, Austria) (Fig. 2B).

\section{Biomechanical testing}

A proximal constrained setup was used (Fig. 2). The embedded specimens were remounted to the aluminium jigs (Fig. 2A(A1)) and aligned within the material testing machine (Fig. 2A(A2); Zwick-Modell Z010/TN2A; Zwick GmbH \& Co. KG, Ulm, Deutschland). Load was applied distally through a 32-mm metal sphere, which enabled free rotation of the distal fragment. It was centred in a centring bore to ensure consistent loading conditions (Fig. 2B). Three markers of a CMS20S ultrasound motion tracking system (Zebris Medical GmbH, Isny im Allgäu, Germany) were mounted to measure residual tilt of the distal fragment (Fig. 2A(A3)).

Specimens were tested to failure using a displacement controlled axial compression test. Following preconditioning to exclude settling effects (preload: $10 \mathrm{~N}$; preconditioning: 10 cycles, $0.2 \mathrm{~mm}$ displacement, $1 \mathrm{~mm} / \mathrm{s}$ ), the specimens were loaded at $1 \mathrm{~mm} / \mathrm{s}$ until either a $20 \%$ force drop or $3 \mathrm{~mm}$ displacement was reached [13, 15]. Photographs and radiographs were taken before and after testing.

\section{Data analysis}

Primary biomechanical stability was assessed by stiffness, elastic limit, and maximum force. These were calculated from the load-displacement curves. Data analysis was conducted automatically in Python using custom scripts as outlined in Fig. 3a. The elastic range was defined as the data range until the coefficient of determination reached its maximum $\left(R^{2}>0.998\right)$. The elastic limit corresponded the last data point of the elastic range. Stiffness was defined as the slope of the regression line within the elastic range. Maximum force was defined as the force where the slope of the tangent line dropped below $95 \%$ of the stiffness. In one case, the slope did not reach this threshold and the global maximum force was chosen. Residual tilt was determined using the motion tracking system to quantify the overall plastic deformation. It was defined as the angle between the initial and final testing position of the distal jig and assessed by rigid registration of the initial and final marker positions (Fig. 3b).

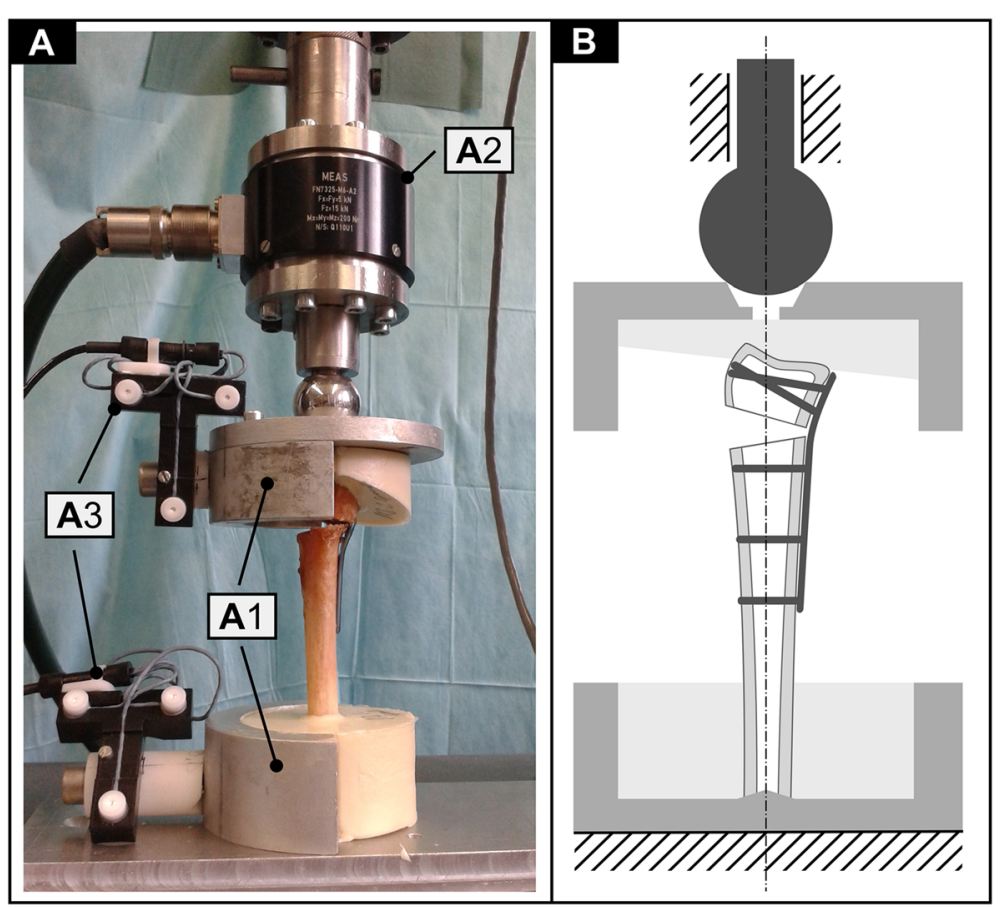

Fig. 2 Illustration of the biomechanical setup (one half of the aluminium jigs were removed to show the embedding). A Photography of the final setup; A1 custom-made aluminium-jigs, A2 multiaxial load cell, A3 Zebris motion tracking system. B Schematic drawing of the final setup illustrating the load axis 


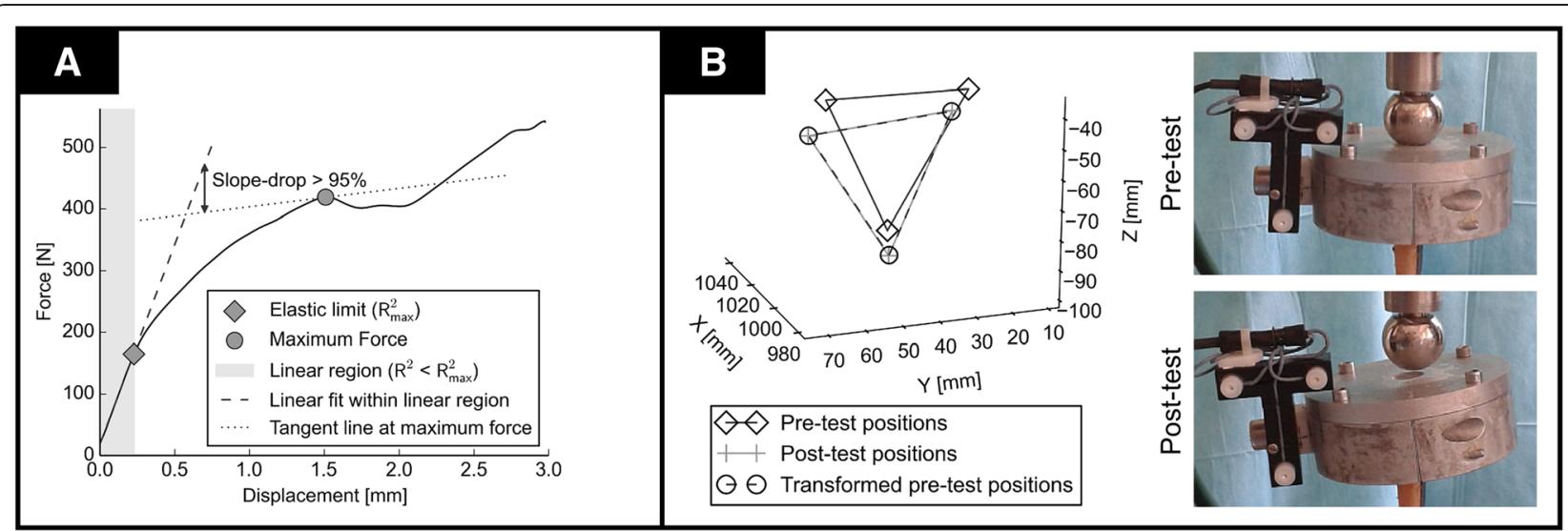

Fig. 3 Analysis of the load-displacement curves and the motion tracking system. A Analysis of a typical force-displacement curve. B Analysis of the residual tilt using the Zebris motion tracking system

\section{Statistics}

In addition to standard descriptive statistics, independent sample $t$ tests were conducted for all biomechanical parameters. Normality and equality of variances for those parameters were tested using the Shapiro-Wilk and $F$ test, respectively. Screw length measurements were not normally distributed and analysed using the Mann-Whitney $U$ test. A Bonferroni correction was applied with an adapted level of significance of 0.0125 to account for multiple testing.

\section{Results}

Two specimens were excluded, one due to previous fracture and one because of misalignment during testing. The mean age of the remaining nine pairs was $85.6 \pm 11.1$ years. Four donors were female. BMD and BMC did not differ between the two groups.

Table 1 shows distal screw length details and statistics for each distal screw separately. Distal screw lengths were significantly greater in group A $(21.7 \pm 2.6 \mathrm{~mm}$; range: 16 to $26 \mathrm{~mm})$ compared to group $\mathrm{B}(16.9 \pm 1.9 \mathrm{~mm}$; range: 12

Table 1 Details on measured and chosen distal screw length [mm]

\begin{tabular}{|c|c|c|c|c|}
\hline Number of screw ${ }^{a}$ & Parameter & Group A100 \% & Group B75 \% & Significance $^{b}$ \\
\hline \multirow[t]{3}{*}{1} & Measured & $20.3 \pm 2.6$ & $19.7 \pm 2.7$ & ns \\
\hline & Chosen & $19.1 \pm 2.7$ & $15.1 \pm 2.0$ & 0.003 \\
\hline & Percent total [\%] & $93.9 \pm 3.7$ & $76.7 \pm 2.8$ & - \\
\hline \multirow[t]{3}{*}{2} & Measured & $23.6 \pm 1.5$ & $24.1 \pm 1.8$ & ns \\
\hline & Chosen & $22.7 \pm 1.4$ & $18.0 \pm 1.4$ & $<0.001$ \\
\hline & Percent total [\%] & $96.0 \pm 3.0$ & $74.8 \pm 2.3$ & - \\
\hline \multirow[t]{3}{*}{3} & Measured & $23.9 \pm 2.0$ & $23.6 \pm 2.4$ & ns \\
\hline & Chosen & $23.3 \pm 2.4$ & $17.8 \pm 1.9$ & $<0.001$ \\
\hline & Percent total [\%] & $97.3 \pm 2.6$ & $75.3 \pm 1.9$ & - \\
\hline \multirow[t]{3}{*}{4} & Measured & $23.3 \pm 2.0$ & $23.1 \pm 1.7$ & ns \\
\hline & Chosen & $22.4 \pm 2.2$ & $17.1 \pm 1.1$ & $<0.001$ \\
\hline & Percent total [\%] & $96.1 \pm 3.0$ & $74.1 \pm 2.0$ & - \\
\hline \multirow[t]{3}{*}{5} & Measured & $21.3 \pm 2.7$ & $21.3 \pm 2.0$ & ns \\
\hline & Chosen & $20.2 \pm 2.3$ & $16.0 \pm 1.7$ & $<0.001$ \\
\hline & Percent total [\%] & $94.9 \pm 3.0$ & $75.1 \pm 2.8$ & - \\
\hline \multirow[t]{3}{*}{8} & Measured & $23.1 \pm 1.8$ & $23.3 \pm 2.2$ & ns \\
\hline & Chosen & $22.2 \pm 2.3$ & $17.6 \pm 1.7$ & $<0.001$ \\
\hline & Percent total [\%] & $96.0 \pm 4.1$ & $75.2 \pm 2.2$ & - \\
\hline
\end{tabular}

Values given in millimetre if not stated differently 
to $20 \mathrm{~mm}$ ). In group $\mathrm{B}$, screws were on average chosen $5.6 \pm 0.9 \mathrm{~mm}$ (range: 3 to $7 \mathrm{~mm}$ ) shorter than measured.

The analysis of the biomechanical outcome parameters revealed no differences between the 75 and $100 \%$ distal screw length group for any parameter (Table 2). Therefore, the null hypothesis had to be rejected. Additional comparison between left and right as well as female and male radii revealed no significant differences for all parameters except a greater residual fragment tilt in female specimen $\left(7.9 \pm 0.8^{\circ}\right.$ vs. $\left.6.6 \pm 0.7^{\circ} ; p=0.001\right)$.

\section{Discussion}

Extensor tendon irritation and attritional tendon ruptures are two of the most common complications following VLPO. Both can be caused by distal screws protruding the dorsal cortex [4-6]. Shorter distal screws can preclude dorsal screw protrusion $[9,10]$. This biomechanical study demonstrated that $75 \%$ distal screw lengths provides similar primary stability to $100 \%$ screw lengths in a cadaver model.

The authors are only aware of two studies, investigating the effect of distal screw length on the primary stability of VLPO, both with inherent limitations. Greenberg et al. [16] presented an abstract at the Annual Meeting of the AAOS comparing three different distal screw lengths: $75 \%, 100 \%$ unicortical, and bicortical. Three fresh-frozen radii were tested per group. No details were given on the biomechanical setup. No group differences were found. The small sample size and the missing information on the setup hinder data interpretation. Wall et al. [11] compared 50, 75, and $100 \%$ unicortical distal screw lengths in synthetic radii. No significant differences between 100 and $75 \%$ distal screw length were reported. However, these conclusions are limited due to the use of synthetic radii in an inadequate fracture model.

In general, the validity of a biomechanical study relies on the test setup used. We tried to apply a bestevidence setup based on previous experiments and literature $[15,13]$. Previous setups vary in almost every aspect, i.e. boundary conditions, the fracture model, and the specimens used [17-20]. All of these have a pronounced impact on the biomechanical outcome parameters. One of these varying parameters is the location of the osteotomy mimicking dorsally unstable distal radius fractures. Its impact on the biomechanical outcome parameters has been highlighted recently [13]. Wall et al. [11] removed a 10$\mathrm{mm}$ dorsal wedge based $10 \mathrm{~mm}$ proximal to Lister's tubercle $[21,19,18]$. Previous studies have removed similar sized wedges 10 to $25 \mathrm{~mm}$ proximal to the articular surface [22-26]. The herein applied standardized fracture model $[15,13]$ bases the osteotomy location on a radiographic study, which has analysed the in vivo distal fracture location in distal radius fractures [14]. We believe that the use of a standardized fracture model $[15,13]$ is a strength of our study. Another decisive parameter for the validity of a biomechanical study is the type of specimen tested. Wall et al. [11] chose a sawbone model (\#1027130, Sawbones; Pacific Laboratories Inc., Vashon, WA, USA), which, although applied in previous studies [27, 21, 28], is not recommended for biomechanical testing by the manufacturers as it does not replicate structural properties of bone. Moreover, a previous study reported a significantly different biomechanical behaviour compared to fresh-frozen radii [13]. Consequently, the use of paired fresh-frozen radii is another strength of this study. A further advantage is the use of paired samples, which allows pair-wise, side-alternating randomization. This ensures a high homogeneity for morphometric and structural parameters.

The results of our study are corroborated by comparison to literature. As outlined above, the biomechanical setups published for distal radius fractures vary significantly. This not only alters the biomechanical behaviour of the mode, which consequently leads to diverging results, but also hampers inter-study comparison. Still, similar maximum force values were reported in previous studies applying a

Table 2 Biomechanical results comparing 75 to $100 \%$ distal screw lengths

\begin{tabular}{|c|c|c|c|c|c|}
\hline Parameter & Parameter & Group & Mean & SD & Sig. \\
\hline \multirow[t]{6}{*}{ Load-displacement curves } & \multirow[t]{2}{*}{ Stiffness [N/mm] } & A (100 \%) & 706 & 103 & \multirow[t]{2}{*}{0.412} \\
\hline & & B (75 \%) & 660 & 124 & \\
\hline & \multirow[t]{2}{*}{ Elastic limit [N] } & A (100 \%) & 177 & 25 & \multirow[t]{2}{*}{0.496} \\
\hline & & B (75 \%) & 167 & 36 & \\
\hline & \multirow[t]{2}{*}{ MaxForce $[\mathrm{N}]$} & A (100 \%) & 493 & 139 & \multirow[t]{2}{*}{0.750} \\
\hline & & B (75 \%) & 471 & 149 & \\
\hline \multirow[t]{2}{*}{ Zebris } & \multirow[t]{2}{*}{ Residual tilt [degree] } & A (100 \%) & 7.3 & 0.7 & \multirow[t]{2}{*}{0.755} \\
\hline & & B (75 \%) & 7.1 & 1.3 & \\
\hline
\end{tabular}

MaxForce: Maximum force as defined as the force when the slope of the tangent line dropped below $0.95 \%$ of the stiffness; A: $100 \%$ unicortical distal screw length (group A); B: $75 \%$ distal screw length (group B)

SD standard deviation, Sig. adjusted (Bonferroni) level of significance 0.0125 
comparable setup [19, 29]. Moreover, the herein observed maximum force values exceeded $250 \mathrm{~N}$ for both groups, which is usually considered the maximum force occurring during rehabilitation [30-32].

Although various biomechanical parameters associated to failure of the osteosynthesis have been assessed, the actual failure mode has not. Possible failure modes include screw-bone, screw-plate, or plate failure. These could be influenced by distal screw length. First, shorter screws reduce the screw-bone contact area, which might increase the local damage around the screws during loading and therefore influence total plastic deformation. In this study, residual tilt was chosen as a surrogate parameter to quantify total plastic deformation [33]. Other studies attempted to quantify residual deformation by the displacement at the fracture gap [34] or along the loading axis [35]. Both parameters are considered less reliable than residual tilt due to their dependence on the specimen's geometry. The herein observed gender differences could be associated to gender differences in BMC or bone geometry. Second, shorter distal screws reduce the screws' lever arm acting on the plate. This could have an impact on the screwplate interface. Screw-plate failure, i.e. screw push-out, is a known complication following polyaxial VLPO [36, 37]. To our best knowledge, no biomechanical study has yet analysed this failure mode. In order to get a first insight, we conducted pre- and post-testing lateral radiographs and photographs to visually evaluate screw push-out (Additional file 1). For group A, five screw push-outs (screws $1(\times 1), 5(\times 2), 8(\times 2))$ occurred in three specimens. For group B, two screw push-outs (screws $5(\times 2))$ occurred in two specimens. Still, screw-plate failure is not only influenced by screw length, but by various parameters, including screw orientation and bone quality. Computational analyses are needed to assess the actual load distribution within the screw-plate construct. This would help to optimize the actual load distribution and thereby increase the construct's overall stability.

A further limitation might be the used axial loading protocol, as it does not account for all loading conditions during early rehabilitation. Although few authors conducted specific bending and torsion tests [38], most biomechanical distal radius fracture studies applied axial compression testing. Constrained axial compression also results in considerable shear forces and moments and is therefore believed to simulate all relevant forces occurring within the construct [39, 40]. Moreover, while some studies applied fatigue testing [39, 11], our goal was the assessment of primary stability, following previous studies $[34,17,13]$. Finally, the influence of distal screw length was only assessed for the most common distal radius fracture (AO-23 A3) using a biomechanical fracture model. Whether this concept can be adapted to fractures in vivo and intra-articular distal radius fractures (AO-23 C) has yet to be evaluated.

\section{Conclusion}

This biomechanical study was able to demonstrate that $75 \%$ distal screw length can provide similar primary stability as unicortical $100 \%$ distal screw length in VLPO. This study, for the first time, provides the biomechanical basis to choose distal screws significantly shorter then measured. Future clinical studies are required to validate this approach in vivo and investigate on the possible reduction of dorsal screw protrusion incidences and subsequent extensor tendon problems.

\section{Additional file}

\section{Additional file 1: Illustration of screw push-out (black arrows). A) Specimen prior to testing; B) specimen after testing; 1) photographs; 2) radiographs.}

\section{Abbreviations}

\#: number; \%: percent; $\times$ : times; ${ }^{\circ}$ : degrees; AO-23 A3: dorsally displaced extra-articular distal radius fractures; $\mathrm{AO}-23 \mathrm{C}$ : dorsally displaced intra-articular distal radius fractures; BMC: bone mineral content; BMD: bone mineral density; HRPQCT: high-resolution peripheral quantitative computer tomography; mg HA: milligramme hydroxyapatite; mm: millimetre; mm/ s: millimetre per second; N: Newton; N/mm: Newton per millimetre; $R^{2}$ : coefficient of determination; VLOP: volar locking plate osteosynthesis.

\section{Competing interests}

Medartis Inc. provided the osteosynthetic material. None of the authors is linked to Medartis (no competing interests) nor has Medartis Inc. been involved in the planning and execution of the study. The study was funded by a research grant of the Medical University of Munich (LMU, FöFoLe \#828). The authors declare that they have no competing interests.

\section{Authors' contributions}

SFB initiated the study, wrote the ethics proposal, conducted the preparation, and wrote the manuscript. AS conducted the biomechanical study and helped with the data analysis and manuscript preparation. HT organized and prepared the specimens and contributed to the study design and preparation of the manuscript. WM helped design the study and prepare the ethics proposal and advised with the statistics and manuscript preparation, DP advised with the biomechanical testing protocol, data processing, and analysis. YC helped to design the study and conduct the testing, provided the biomechanical testing environment, and helped with the manuscript preparation. All authors conducted proofreading an approved the final manuscript.

\section{Acknowledgements}

We would like to thank Medartis Inc. who provided the osteosynthetic material. The study was funded by a research grant of the Medical University of Munich (LMU, FöFoLe \#828). We would especially like to thank Mr. Dipl. Ing. Christian Schröder for his advice and help in manufacturing the testing setup.

\section{Author details}

${ }^{1}$ Department of Trauma Surgery, University Hospital of Munich (LMU), Campus Innenstadt, Nußbaumstrasse 20, 80336 Munich, Germany. ${ }^{2}$ Institute of Lightweight Design and Structural Biomechanics, Vienna University of Technology, Getreidemarkt 9, 1060 Vienna, Austria. ${ }^{3}$ Center of Anatomy and Cell Biology, Department of Systematic Anatomy, Medical University Vienna, Währinger Straße 13, 1090 Vienna, Austria. ${ }^{4}$ Department of Orthopedic Surgery, Physical Medicine and Rehabilitation, University Hospital of Munich (LMU), Campus Großhadern, Marchioninistrasse 15, 81377 Munich, Germany.

Received: 18 June 2015 Accepted: 27 August 2015

Published online: 08 September 2015 


\section{References}

1. Knudsen R, Bahadirov Z, Damborg F. High rate of complications following volar plating of distal radius fractures. Dan Med J. 2014;61(10):A4906.

2. Bentohami A, De Burlet K, De Korte N, van den Bekerom MPJ, Goslings JC Schep NWL. Complications following volar locking plate fixation for distal radial fractures: a systematic review. J Hand Surg Eur. 2014;39(7):745-54. doi:10.1177/1753193413511936

3. Arora R, Lutz M, Deml C, Krappinger D, Haug L, Gabl M. A prospective randomized trial comparing nonoperative treatment with volar locking plate fixation for displaced and unstable distal radial fractures in patients sixty-five years of age and older. J Bone Joint Surg Am. 2011;93(23):2146-53. doi:10.2106/JBJS.J.01597.

4. Arora R, Lutz M, Hennerbichler A, Krappinger D, Espen D, Gabl M. Complications following internal fixation of unstable distal radius fracture with a palmar locking-plate. J Orthop Trauma. 2007;21(5):316-22. doi:10.1097/BOT.0b013e318059b993.

5. Drobetz $\mathrm{H}$, Kutscha-Lissberg E. Osteosynthesis of distal radial fractures with a volar locking screw plate system. Int Orthop. 2003;27(1):1-6. doi:10.1007/s00264-002-0393-x.

6. Berglund LM, Messer TM. Complications of volar plate fixation for managing distal radius fractures. J Am Acad Orthop Surg. 2009;17(6):369-77.

7. Flinkkilä T, Sirniö K, Hippi M, Hartonen S, Ruuhela R, Ohtonen P, et al. Epidemiology and seasonal variation of distal radius fractures in Oulu. Finland Osteoporos Int. 2011;22(8):2307-12. doi:10.1007/s00198-010-1463-3.

8. Plant CE, Hickson C, Hedley H, Parsons NR, Costa ML. Is it time to revisit the $\mathrm{AO}$ classification of fractures of the distal radius? Inter- and intra-observer reliability of the AO classification. Bone Joint J. 2015;97-B(6):818-23. doi:10.1302/0301-620X.97B6.33844.

9. Jupiter J, Rikli D, Fricker R, Jupiter J, Kastelec M. Distal radius 23-A2.2 ORIF Palmar Plating. AO Foundation Surgical References. Editor: Steve Krikler. AO-Foundation: Switzerland; 2014. https://www2.aofoundation.org/wps/ portal/!ut/p/a1/04_Sj9CPykssy0xPLMnMzOvMAfGjzOKN_A0M3D2DDbz9_ UMMDRyDXQ3dw9wMDAwCTYEKIvEocDQnTr8BDuBoQEE_I35Uek5EtCp4U76UdqqBolReekgUx3zkowt0vWjilLTUotSi_Qy8otL9CPKy8uN9BLz0_ JL81LAftTLLOrXL8gNjajyLHYEAJqV_LU!/dI5/d5/LOIDU0IKSWdrbUEhIS9JRF JBQUIpQ2dBek15cXchLzRKQ2hEb01kdshowPage=redfix\&bone=Radius\& segment=Distal\&classification=23-A2.2\&treatment=operative\&method=ORIF +-+Open+reduction+internal+fixation\&implantstype=Palmar+plating \&approach=\&redfix_url=

10. Perez EA. Fractures of the shoulder, arm, and forearm. 12th ed. Philadelphia: Campbell's Operative Orthopaedics; 2012. p. 2819-916.

11. Wall LB, Brodt MD, Silva MJ, Boyer MI, Calfee RP. The effects of screw length on stability of simulated osteoporotic distal radius fractures fixed with volar locking plates. J Hand Surg [Am]. 2012;37(3):446-53. doi:10.1016/j.jhsa.2011.12.013.

12. Varga P, Pahr DH, Baumbach S, Zysset PK. HR-pQCT based FE analysis of the most distal radius section provides an improved prediction of Colles fracture load in vitro. Bone. 2010;47(5):982-8. doi:10.1016/j.bone.2010.08.002.

13. Baumbach SF, Dall Ara E, Weninger $P$, Antoni $A$, Traxler $H$, Dörr $M$, et al. Assessment of a novel biomechanical fracture model for distal radius fractures. BMC Musculoskelet Disord. 2012;13(1):252. doi:10.1186/1471-2474-13-252.

14. Baumbach SF, Schmidt R, Varga P, Heinz T, Vécsei V, Zysset PK. Where is the distal fracture line location of dorsally displaced distal radius fractures? J Orthop Res. 2011;29(4):489-94. doi:10.1002/jor.21268.

15. Varga P, Baumbach S, Pahr D, Zysset PK. Validation of an anatomy specific finite element model of Colles' fracture. J Biomech. 2009;42(11):1726-31. doi:10.1016/j.jbiomech.2009.04.017.

16. Greenberg JA, Warden S, Izadi KD. The effect of screw length on fracture stability in volar locked plating of distal radius fractures. Annual Meeting of the American Association of Orthopaedic Surgeons. 2010.

17. Hart A, Collins M, Chhatwal D, Steffen T, Harvey EJ, Martineau PA. Can the use of variable-angle volar locking plates compensate for suboptimal plate positioning in unstable distal radius fractures? A biomechanical study. J Orthop Trauma. 2015;29(1):e1-6. doi:10.1097/BOT.0000000000000146.

18. Sokol SC, Amanatullah DF, Curtiss S, Szabo RM. Biomechanical properties of volar hybrid and locked plate fixation in distal radius fractures. J Hand Surg [Am]. 2011;36(4):591-7. doi:10.1016/j.jhsa.2010.12.032.

19. Mehling I, Müller LP, Delinsky K, Mehler D, Burkhart KJ, Rommens PM. Number and locations of screw fixation for volar fixed-angle plating of distal radius fractures: biomechanical study. J Hand Surg [Am]. 2010;35(6):885-91. doi:10.1016/j.jhsa.2010.03.027.
20. Chen L, Dai Q, Wongworawat MD. A biomechanical comparison between two volar locking plate systems for distal radius fractures. Orthopedics. 2006;29(10):927-9.

21. Weninger $P$, Schueller $M$, Drobetz $H$, Jamek $M$, Redl $H$, Tschegg E. Influence of an additional locking screw on fracture reduction after volar fixed-angle plating-introduction of the "protection screw" in an extra-articular distal radius fracture model. J Trauma. 2009:67(4):746-51. doi:10.1097/TA.0b013e3181a8b238.

22. Kandemir U, Matityahu A, Desai R, Puttlitz C. Does a volar locking plate provide equivalent stability as a dorsal nonlocking plate in a dorsally comminuted distal radius fracture?: a biomechanical study. J Orthop Trauma. 2008;22(9):605-10. doi:10.1097/BOT.0b013e318186006f.

23. Koh S, Morris RP, Patterson RM, Kearney JP, Buford WL, Viegas SF. Volar fixation for dorsally angulated extra-articular fractures of the distal radius: a biomechanical study. J Hand Surg [Am]. 2006;31(5):771-9. doi:10.1016/ j.jhsa.2006.02.015.

24. Dunning CE, Lindsay CS, Bicknell RT, Johnson JA, King GJ, Patterson SD. Ilizarov hybrid external fixation for fractures of the distal radius: part II. Internal fixation versus llizarov hybrid external fixation: stability as assessed by cadaveric simulated motion testing. J Hand Surg [Am]. 2001;26(2):218-27. doi:10.1053/jhsu.2001.22925.

25. Gesensway D, Putnam MD, Mente PL, Lewis JL. Design and biomechanics of a plate for the distal radius. J Hand Surg [Am]. 1995;20(6):1021-7.

26. Ekenstam F, Hagert CG. The distal radio ulnar joint. The influence of geometry and ligament on simulated Colles' fracture. An experimental study. Scand J Plast Reconstr Surg. 1985;19(1):27-31.

27. Martineau PA, Waitayawinyu T, Malone KJ, Hanel DP, Trumble TE. Volar plating of AO C3 distal radius fractures: biomechanical evaluation of locking screw and locking smooth peg configurations. J Hand Surg [Am]. 2008;33(6):827-34. doi:10.1016/j.jhsa.2008.01.006.

28. Willis AA, Kutsumi K, Zobitz ME, Cooney WP. Internal fixation of dorsally displaced fractures of the distal part of the radius. A biomechanical analysis of volar plate fracture stability. J Bone Joint Surg Am. 2006;88(11):2411-7. doi:10.2106/JBJS.E.00946.

29. Blythe M, Stoffel K, Jarrett P, Kuster M. Volar versus dorsal locking plates with and without radial styloid locking plates for the fixation of dorsally comminuted distal radius fractures: a biomechanical study in cadavers. J Hand Surg [Am]. 2006;31(10):1587-93. doi:10.1016/j.jhsa.2006.09.011.

30. Klitscher D, Mehling I, Nowak L, Nowak T, Rommens PM, Müller LP. Biomechanical comparison of dorsal nail plate versus screw and K-wire construct for extra-articular distal radius fractures in a cadaver bone model. J Hand Surg [Am]. 2010;35(4):611-8. doi:10.1016/j.jhsa.2010.01.018.

31. Osada D, Fujita S, Tamai K, Iwamoto A, Tomizawa K, Saotome K. Biomechanics in uniaxial compression of three distal radius volar plates. J Hand Surg [Am]. 2004;29(3):446-51. doi:10.1016/j.jhsa.2003.12.010.

32. Rikli DA, Honigmann P, Babst R, Cristalli A, Morlock MM, Mittlmeier T. Intra-articular pressure measurement in the radioulnocarpal joint using a novel sensor: in vitro and in vivo results. J Hand Surg [Am]. 2007;32(1):67-75. doi:10.1016/j.jhsa.2006.10.007.

33. Drobetz H, Schueller M, Tschegg EK, Heal C, Redl H, Muller R. Influence of screw diameter and number on reduction loss after plating of distal radius fractures. ANZ J Surg. 2011;81(1-2):46-51. doi:10.1111/j.1445-2197.2010.05479.x.

34. Crosby SN, Fletcher ND, Yap ER, Lee DH. The mechanical stability of extra-articular distal radius fractures with respect to the number of screws securing the distal fragment. J Hand Surg [Am]. 2013;38(6):1097-105. doi:10.1016/j.jhsa.2013.02.038.

35. Rausch S, Klos K, Stephan H, Hoffmeier K, Gras F, Windolf M, et al. Evaluation of a polyaxial angle-stable volar plate in a distal radius C-fracture model-a biomechanical study. Injury. 2011;42(11):1248-52. doi:10.1016/j.injury.2010.12.005.

36. von Recum J, Matschke S, Jupiter JB, Ring D, Souer J-S, Huber M, et al. Characteristics of two different locking compression plates in the volar fixation of complex articular distal radius fractures. Bone Joint Res. 2012;1(6):111-7. doi:10.1302/2046-3758.16.2000008.

37. Fowler JR, llyas AM. Prospective evaluation of distal radius fractures treated with variable-angle volar locking plates. J Hand Surg [Am]. 2013;38(11):2198-203. doi:10.1016/j.jhsa.2013.08.116.

38. Weninger $P$, Dall'ara $E$, Leixnering $M$, Pezzei $C$, Hertz $H$, Drobetz $H$, et al. Volar fixed-angle plating of extra-articular distal radius fractures-a biomechanical analysis comparing threaded screws and smooth pegs. J Trauma. 2010;69(5):E46-55. doi:10.1097/TA.0b013e3181c6630e.

39. Drobetz $H$, Weninger $P$, Grant $C$, Heal C, Muller R, Schuetz M, et al. More is not necessarily better. A biomechanical study on distal screw numbers in 
volar locking distal radius plates. Injury. 2013;44(4):535-9. doi:10.1016/j.injury.2012.10.012

40. Rausch S, Schlonski O, Klos K, Gras F, Gueorguiev B, Hofmann GO et al. Volar versus dorsal latest-generation variable-angle locking plates for the fixation of AO type 23C 2.1 distal radius fractures: a biomechanical study in cadavers. Injury. 2012. doi:10.1016/j.injury.2012.08.048.

Submit your next manuscript to BioMed Central and take full advantage of:

- Convenient online submission

- Thorough peer review

- No space constraints or color figure charges

- Immediate publication on acceptance

- Inclusion in PubMed, CAS, Scopus and Google Scholar

- Research which is freely available for redistribution 